\title{
Intelligent Driver Profiling System for Cars - A Basic Concept
}

\author{
Nermin Caber $^{1}$, Patrick Langdon ${ }^{1}$ and P. John Clarkson ${ }^{1}$ \\ ${ }^{1}$ Engineering Design Centre, University of Cambridge, Department of Engineering \\ Trumpington Street, Cambridge CB2 1PZ, United Kingdom \\ \{nc501, pml24, pjc10\}@cam.ac.uk
}

\begin{abstract}
Many industries have been transformed by the provision of service solutions characterised by personalisation and customisation - most dramatically the development of the iPhone. Personalisation and customisation stand to make an impact on cars and mobility in comparable ways. The automobile industry has a major role to play in this change, with moves towards electric vehicles, autonomous cars, and car sharing as a service. These developments are likely to bring disruptive changes to the business of car manufacturers as well as to drivers. However, in the automobile industry, both the user's preferences and demands and also safety issues need to be confronted since the frequent use of different makes and models of cars, implied by car sharing, entails several risks due to variations in car controls depending on the manufacturer. Two constituencies, in particular, are likely to experience even more difficulties than they already do at present, namely older people and those with capability variations. To overcome these challenges, and as a means to empower a wide car user base, the paper here presents a basic concept of an intelligent driver profiling system for cars: the system would enable various car characteristics to be tailored according to individual driver-dependent profiles. It is intended that wherever possible the system will personalise the characteristics of individual car components; where this is not possible, however, an initial customisation will be performed.
\end{abstract}

Keywords: Automotive Engineering and Technology, Advanced Driver Assistance Systems, Car Driver Profiling, Customisation, Personalisation, Inclusive Design, Human Factors and Ergonomics.

\section{Introduction}

With the move to increased usage of car sharing services, it is crucial to reflect on the factor of transportation safety. Every day about 3,000 people are killed in road traffic crashes, resulting in up to 1.8 million deaths per year according to the World Health Organization [1]; a majority of these accidents can be attributed to human errors [2]. Since car manufacturers lack sufficient data, knowledge and understanding concerning users' motor, sensory and cognitive capabilities and limitations, they complicate driving for the majority of users and, thus, help facilitate those kinds of errors. However, technology is now at a stage where it may accommodate the wide range of diversity among 
car users, leading to increased safety. This becomes even more important when people use different vehicles with varying controls, as is the case with car sharing services, and, thus, do not have previous experience of the car they use. In cases where fundamental controls for driving differ, such as the utilisation of windscreen wipers or the reverse gear, a considerable effect on safety can be expected.

In every sector, whether that of smartphones, computers, furnishings or cars, the importance of customisation and personalisation is increasing significantly; people prefer, as far as possible, to have products perfectly tailored to their demands and needs [3-6]. This can be done either by customisation or by personalisation; while in customisation the user decides on product characteristics, in personalisation this is derived from information gathered about the user. Amazon, utilising user data to make personalised product suggestions, is a good example for personalisation, while Dell, enabling their customers to customise their computer, is an example for customisation [4]. Within the car industry, the circumstance of users wanting personalised features is gaining importance as engineering progress begins to allow autonomous driving. In consequence, this is radically changing Human Machine Interface (HMI) as both customisation and personalisation are further driven by the continuing growth of car sharing, a growth which can partly be attributed to the car's decreasing importance as a social status symbol for most people [7-10]. In the future, there may be less privately owned cars and more shared ones. Mobility may become a service, often called 'Mobility as a Service' (MAAS), and might change the business model of car manufacturers significantly.

Today, the ability to select different driving modes already allows a driver to customise various characteristics of the car such as the suspension, the response qualities of the engine and the gearbox, the steering, and advanced driver assistance systems (e.g. Electronic Stability Control (ESC)). Several such characteristics, including steering wheel and seat position, only have to be adjusted once as they can be memorized by the car and associated with the car keys, making readjustment, e.g. after someone else has driven the car, unnecessary. Most of these systems are able to save multiple drivers, generally up to three, per key. However, this single modal approach is extremely sensitive to errors since, e.g. in corporate automobile fleets or families, several people often use the same car and share keys thus leading to false customisation of the car. For use in car sharing those systems have to be based on the user's card applied to unlock the car; to the best knowledge of the authors, such a system has not been applied yet. Nevertheless, these systems cannot be termed intelligent, are mostly based on customisation, and tailor only a small scope of areas.

To meet all these challenges, it is proposed that a system be developed, which goes a step further than current systems and implements automatic personalisation in all feasible areas of a car; if personalisation is not achievable, a driver-dependent customisation is intended. More precisely, the research, this paper is based on, aims to conceptually design an intelligent driver profiling system for cars through trials of alternative techniques fulfilling a specific sub-function, as well as of integral concepts, and through the usage of an inclusive design approach ensuring the inclusion of a wider population. By considering a wider population, including the elderly and those with capability variations, such a system will empower car users and, as a consequence, will constitute a 
profound solution for the safety problem since this system is able to facilitate driving for a majority of people and, as a result, be safer. Such a system, moreover, paves the way for MAAS and, thus, will increase customer satisfaction due to the preference for personalised and customised items [6]. Both car manufacturers and society benefit from this; car manufacturers are able to increase business and society enjoys higher satisfaction alongside safer driving.

This paper introduces the topic of an intelligent driver profiling system for cars by presenting the state of the art in this field as well as related ones, and by elaborating a basic concept for such a system.

\section{State of the Art}

Although several adjustments in current cars can be memorised and recalled based on the driver's key or profile, the intended system aims at extending this customisation approach and adding personalisation in all feasible areas. Contemporary cars already utilise various applications potentially helpful for the development of such an intelligent driver profiling system for cars. Some of these systems can constitute potential sub-systems adapted by and implemented in the driver profiling system, or the sensors used by these systems to fulfil their task can be helpful in creating profile data necessary for other profile-based adjustments.

\subsection{Automotive Sensors}

Modern cars are equipped with a huge amount of sensors measuring several parameters within chassis, body, and power train areas; for instance, contemporary luxury cars are equipped with more than 100 sensors per vehicle [11]. Generally, two kinds of sensors are distinguished: proprioceptive measuring in-vehicle data and exteroceptive, such as video, lidar, or radar, observing vehicle environment [9]. While in the first half of the 20th century cars did not have any kind of sensors, in the 1970s car companies started to implement sensor equipment and increased the amount significantly over the years; this growth is driven by rising requirements in several fields [12]. Sensors in power train systems ensure optimal car performance and the compliance with statutory provisions, e.g., emission restrictions. In chassis systems, sensors mainly serve safety, stability, weight reduction, and legislation reasons; for example, the United States government demands, since September 2007, a Tire Pressure Monitoring System (TPMS), which uses a pressure sensor on each wheel to detect a possible pressure drop in the tires, in all new cars. Body sensors generally aim for increased security, occupant safety, comfort and convenience by, for example, applying night vision sensors which detect potential hazards beyond the lighting range of the car's headlights and, thus, support driver's awareness. All current safety systems such as Electronic Stability Control (ESC), Antilock Brake System (ABS) and advanced airbags use multiple sensors; some of the collected data can be useful for the intended driver profiling system, as in the case of advanced airbags [11, 13, 14]. In this case, sensors measure the seat position, the seatbelt tension, and the seated weight, to derive specific information about the 
driver [11]. This example already indicates the potential of in-vehicle sensor data gathering; a thorough analysis in this area in further research will reveal a variety of data enabling to derive various driver characteristics.

\subsection{Advanced Driver Assistance Systems}

Advanced driver assistance systems aim to increase safety and support drivers by supplying relevant information about the environment, providing warnings in risky situations and automating some driving tasks to excuse the driver from manual control [15]. In other words, while some ADAS only provide visual, haptic or audible warnings, other ADAS actively intervene in control when a potential risk is detected [16]. Research conducted on the effectiveness of semi-autonomous ADAS demonstrated the safety improvement in emergency situations [17].

All that started back in 1978 with the production of the Antilock Braking System (ABS) invented by Bosch, the first actively engaging assistance system. Since then multiple ADAS such as ESC, Parking Assistance Systems, Adaptive Cruise Control, Forward Collision Prevention Systems, Lane Departure Warning (LDW) Systems, and Traffic Jam Assistance Systems have been introduced to the market [9]. In the next step, these systems are combined with a driver status monitoring system to enable an automated activation in the case of an abnormal driver's state [18].

Up to date, most ADAS operate autonomously without communicating with ADAS from other cars or the road infrastructure; however, in the future a cooperative approach is sought, enabling continuous Car2Car and Car2X communication. Such cooperative driving permits the exchange of information to communicate, for example, slowdowns or congestions to rear traffic which is not aware of the hazard; in this way, information not measurable with in-vehicle sensors can be gathered $[9,15]$. The usage of such ADAS in the context of an intelligent driver profiling system for cars allows, on the one side, to support drivers with specific limitations, and, on the other side, to tailor these systems to the driver's profile so that an even greater safety benefit and customer satisfaction can be achieved [5]. ESC, for example, can already be customised in modern cars by authorising the driver to choose between specific system settings, such as normal, sport, and race mode.

\subsection{Driver Behaviour Profiling}

The state of the art in driver behaviour profiling focuses on the use of in-vehicle and in some cases external sensors, such as smartphones, to analyse driver behaviour; these systems try to detect risky or aggressive drivers in order to support fleet management targeting to reduce fleet degradation and costs, insurance companies aiming for driverdependent premiums, and economical as well as safe driving [19, 20]. When using invehicle sensors most approaches rely on Controller Area Network Bus (CAN Bus) data to retrieve proprioceptive as well as exteroceptive measurements and to fuse this data [21-24]. Gathering a variety of data allows to more precisely judge the risk of a certain driving behaviour [25]. In the case of the application of external sensors, the same method of broad gathering is applied [26, 27]. Another possibility of data gathering is 
the installation of an external data recording system. Many insurance companies use these devices to enable driver dependent premiums [28, 29]. The calculation of such a driver behaviour profile delivers valuable data that can be used for the computation of the more comprehensive driver profile aimed at by the intended system. In contrast to driver behaviour profiling, the intended system suggested in this paper aims to implement a broader system that not only analyses driver's behaviour but also takes into account driver's capabilities, needs, schedule, preferences, state and so on; the goal is a highly tailored car allowing optimal utilisation of MAAS and enhanced user satisfaction and safety.

\subsection{Driver State Monitoring}

Since multiple fatalities are caused by driver's inattention, a wide range of research has been performed on implementing a driver state monitoring system, also known under the terms driver impairment monitor, driver inattention monitor or driver vigilance monitoring; the term driver state includes all kinds of distraction or fatigue possibly occurring. In autonomous cars currently used indirect inattention systems measuring driving performance metrics will no longer be feasible, making the investigation of new direct approaches essential. Promising approaches observe the driver and assess, based on distinct visual, auditory, mechanical and cognitive characteristics, whether the driver is distracted or fatigued. Most of these systems use modern camera technology and image processing in order to evaluate possible distraction based on eye and head movement [30-36]. The next level of state monitoring does not only include the further improvement of general distraction or fatigue assessment but goes one step further and aims to detect complex mental states [37]. Such systems are crucial for a potential intelligent driver profiling system for cars since the information provided is required to enable car characteristic adjustments based on the driver's physical as well as mental conditions. Fusing the data gathered by the driver state monitoring system with additional profile based information about the user, such as age, diseases, biometrics and capabilities, enables a more robust and earlier detection.

\section{Basic Concept}

\subsection{Motivation}

It is believed that the way people travel will change significantly within the next decades; the majority of people will switch from privately owned to shared or rented cars. Whenever people plan to travel, they will book a car and use this to get from one place to the other instead of utilising their own car; already in large cities, cars provided by car sharing services may be found within a short walking distance from nearly every point. Some car manufacturers have already started to offer car sharing services (see DriveNow (BMW MINI \& Sixt) and Car2Go (Daimler)) since they are aware of the trend towards MAAS, especially, within the younger generation for whom cars do not represent an important social status symbol. A consequence of this shift is a frequent change of the cars people drive; accordingly, people will drive cars they are not familiar 
with resulting in potential safety hazards. Up to date, even for some fundamental controls, such as the use of windscreen wipers or the reverse gear, no standard has been implemented. For example, when a car sharing customer drives a car he is not familiar with on the highway and a sudden shower of rain appears, he must know how to activate the windscreen wipers because otherwise the driving performance is deteriorated significantly. Another example is the case of older people who have driven a special car brand perhaps for decades and, therefore, are used to the controls of this car brand; they probably will experience severe difficulties when faced with divergent controls in a shared car. Although people will learn the utilisation of controls depending on the car brand, this process can be annoying for the user and is prone to failure. Consequently, an intelligent driver profiling system for cars identifying the user and adjusting car characteristics based on the user's preferences can increase safety as well as customer satisfaction and gives the car manufacturers implementing such a system first a competitive advantage. Therefore, in the long run this research aims to deliver and trial different techniques for and concepts of an intelligent driver profiling system for cars in order to contribute to MAAS and to increase safety, comfort and customer satisfaction $[19,20]$. Thereby, car manufacturers as well as society benefit from such a system.

\subsection{Remit and Research Approach}

The aspiration here is a device or system able to adjust car characteristics perfectly to the user's preferences, capabilities and limitations; the system shall be able to transmit the profile information between cars in order to be car-independent. Based on personalisation and customisation, the system shall tailor the car as the user approaches it. Any technical solution is likely to be based around elements of the vehicle control system. Based on current knowledge and research, the following remit can be derived:

1. Identifying the user

2. Gathering data from the vehicle about the user

3. Allowing customisation of areas by data obtained from direct user input during use

4. Calculating a profile based on the data gathered as well as on the user's customisation

5. Tailoring all adjustable car characteristics based on the profile

6 . Updating the profile continuously based on new data gathered or entered by a customer

7. Storing the data

In this research project the inclusive design approach is equated with the humancentred design approach since it is understood that these two approaches mainly differ in their scope; while human-centred design focuses on the potential target users, inclusive design extends this idea and aims to target the widest possible audience including people with capability impairments, perhaps as a result of ageing [38-40]. Since a great part of the population drives and, therefore, only few people can be expelled, the design process in this research pursues such an inclusive design approach; this ensures that user experience is considered a crucial part of design [1,38]. As a consequence, user acceptance as well as the perceived benefit of an intelligent driver profiling system for 
cars are increased. In this way, it is ensured that especially those people, who experience most difficulties when driving, are considered in the design. Accordingly, establishing the needs, wants and expectations of possible end-users, including those who have no experience of personalised devices and possibly no needs for such features, will be an important part of this research.

The prospective research in this field aims to handle this challenge by answering the central research question:

How is it possible to improve user satisfaction and performance using an intelligent driver profiling system for cars based on customisation and personalisation?

The process to answer this research question and to achieve the conceptual design of an intelligent driver profiling system for cars mainly comprises eight key work packages: (1) ascertainment of the current state of the art, (2) identification of end-user's requirements and needs, (3) clarification of hypotheses and research questions, (4) development of a research methodology, (5) definition of a hypothetical intelligent driver profiling system for cars, (6) development of a design specification, (7) development of a detailed conceptual design, and (8) the evaluation of the design's benefits. With this approach mainly the following research sub-questions are addressed:

- What is the current state of the art?

- What are the end-users' needs, preferences, wants, limitations, characteristics and capabilities?

- What does a hypothetical intelligent driver profiling system for cars look like?

\subsection{Visualisation of intended System}

To visualise the remit and objective of the intended system, a juxtaposition of the present and the prospective human-car-interaction is sketched, using the example of a car rental scenario. Based on the Hierarchical Task Analysis of Driving (HTAoD) developed by [41] and personas, the tasks to be fulfilled are addressed and examined successively from a present and a future perspective in order to give an overview of the system's functions and potential benefits. Personas constitute detailed caricatures facilitating the visualisation of user's needs, demands, capabilities, and limitations, and are a common methodology applied in human-centred design [38].

Richard, a 67-year-old German man, and his wife, Gudrun (65 years old), are travelling to Majorca. Both retired last year from their jobs and want to enjoy their new freedom; Richard worked as an electrical engineer while Gudrun was a language teacher. They have driven Mercedes-Benz cars over decades and are used to its controls; currently, they drive a 2017 Mercedes-Benz C220d. They are both afflicted with age related long sightedness. Although both have got a smartphone, they are not exceptionally interested in digital technology and find it difficult to learn how to use sophisticated interfaces or interfaces not meeting their expectation. The couple have never been to Majorca before and are, consequently, unfamiliar with the airport and 
the destination. After arriving at the airport, they hire a car to get to their hotel. During this trip they meet several challenges.

After getting the key from the customer service, Richard and Gudrun, at first, have to find their rental car in a multi-storey car park. The customer service assistant told them the registration number, the storey the car is parked on, and the brand and model of the car; however, since the couple do not know how a Jaguar XF looks like they only can focus on the registration number to find the car on the specific storey. Under current circumstances, this task is annoying and time-consuming. Richard and Gudrun run all over the place and use the opening and closing buttons of the car key to observe opening and/or closing indication and, in that way, to facilitate the search for the car.

In the next step, after entering the car, Richard has to adjust the driver's seat and the mirrors to his preferences. Richard hunts for the controls to adjust the longitudinal position, the backrest, and the head restraint of the seat; however, he cannot find the controls. What Richard does not realise is that, in contrast to his Mercedes-Benz where the power seat control switches are placed at the door panel, the control switches of the Jaguar are located on the side of the seat valance. In order to adjust his seat, Richard calls the customer service assistant for help; the assistant helps him to adapt the seat position as well as the mirrors. Although Richard behaves properly in this situation and asks for help, the chance of someone relinquishing the seat adjustment and driving without accurately adjusted seat and mirrors is high; this constitutes a severe driving risk.

After adjusting seats and mirrors, Richard tries to start the Jaguar XF. Based on experience with his current Mercedes-Benz and the cars before it, he hunts for the ignition switch barrel to put the car key into it; however, he is not able to find it since the Jaguar is equipped with keyless entry. After a while Gudrun brings the 'Start Engine Stop' button to Richard's attention and he presses the button to start the engine. While the engine does not start, Richard notices a message in the dashboard he cannot read and asks Gudrun for his reading glasses. When reading the message, Richard realises that the language is Spanish and asks Gudrun for help to translate it. Since the car asks Richard to press the brake pedal, he does that and, concurrently, pushes the 'Start Engine Stop' button to start the engine. Although in this example the information presented in the dashboard is not correlated to safety and the car does not move, in other examples, such as driving on a highway and loosing pressure in one tire, not being able to read a warning message informing the driver, for example about a tire pressure drop, can, indeed, deteriorate the driving safety.

Since Richard and Gudrun have not been to Majorca, yet, they are frightened of not being able to handle the navigation system of the Jaguar XF. Nevertheless, they try to enter the address of their hotel into the navigation system. Out of habit, he spins the rotary control knob on the transmission hump to scroll through the menu. Because of flashing up symbols on the 
dashboard, he, immediately, realises that he operates the automatic gear box instead of the infotainment system. In consequence of this confusion, they, based on their experience with smartphones, try to handle the infotainment system by touching the display and discover that it works. Now, they are able to enter their hotel address into the navigation system although the different menu structure and Spanish address format confuse them and make the task time-consuming and annoying.

On their route to the hotel Richard notices his increasing fatigue and deteriorating awareness since he and Gudrun have already travelled for several hours since leaving their home in Germany. In the same moment the driver condition monitoring system warns Richard against his drowsiness. Therefore, Richard and Gudrun decide to take a break before continuing their journey and to exchange positions. After adjusting her seat and the mirrors, Gudrun takes over control and drives them safely to the hotel. Although current driver drowsiness warning systems function well, they cannot detect drowsiness until the driving performance has deteriorated already.

Such a scenario occurs every day in the world and exacerbates people's journeys. Especially older people and those with capability variations are afflicted by these challenges. However, even younger and/or intellectual people sometimes struggle with tasks due to disinterest or lack of knowledge in the specific field. Without further discussion, we can agree that such a scenario is not desirable. Hence, the question arises how it might look like with an intelligent driver profiling system.

After getting the key from the customer service, Richard and Gudrun, at first, have to find their rental car in a multi-storey car park. The customer service assistant told them the registration number, the storey the car is parked on, and the brand and model of the car. When arriving at the correct floor, the intelligent driver profiling system guides Richard and Gudrun directly to the car. This might be by voice and/or visual instructions performed by either a car key or a customer's smartphone. Besides displaying the visual instruction on the screen of the car key or smartphone, the device may be able to display the instructions on the floor and to tell them the exact position of the car by, for example, saying 'Your Jaguar XF is parked in the fourth parking on the left side'. When approaching the car, it indicates its location visually as well as aurally and opens automatically for the couple.

In the next step, when entering the car, Richard realises that the seat is reversed and starts adjusting to his preferred position as he sits down; he immediately feels extremely comfortable. Based on the profile which might know about Richard's anthropometry, the car adjusts the seat and the mirrors fitting Richard's preferences. Moreover, since the system is familiar with the age of Richard and Gudrun, it reverses the seats to facilitate the entry before it moves them into driving position. If Richard decides that the seating position is not optimal, he is able to adjust the seat by, for example, voice control and the system might align his anthropometry information in the deposited profile. At first use, the question arises whether to acquire the anthropometry by sophisticated sensors scanning the user, this means personalisation, or by 
an initial manual data input performed directly by the user, this means customisation. This question has to be explored in prospective research.

After adjusting seats and mirrors, Richard tries to start the Jaguar XF. The intelligent driver profiling system communicates to Richard how to start the engine by, for instance, voice and/or visual instructions and, in that way, helps him to understand the system. With ease Richard starts the engine. Understandably, the system uses visual as well as voice instructions in English; the visual instructions, furthermore, are in a readable font size for Richard, making use of reading glasses unnecessary. An exemplary instruction might be 'Richard, please press the brake pedal and then press the "Start Engine Stop" button positioned on the transmission hump and highlighted by a pulsating red circle'. All this might be possible since the profile is aware of the user's capabilities and personalises the adaptive interface accordingly. The intended system will try to avoid any complex information procurement and misunderstanding in order to facilitate the driving task and, in consequence, to increase user satisfaction.

Since Richard and Gudrun have not been to Majorca, yet, they are frightened of not being able to handle the navigation system of the Jaguar XF. However, after starting the car Richard and Gudrun are asked visually and aurally whether they want to be guided directly to their hotel or whether they want to render an intermediate stop. They decide to drive to the hotel directly; therefore, the system automatically enters the address of the hotel into the navigation system. The intelligent driver profiling system may be connected to their smartphones and, thus, be aware of Richard's and Gudrun's destination. If they had wanted to render an intermediate stop, the system would have asked for the new destination, elucidated the Spanish address format, explained how to use the infotainment system, and adjusted the adaptive interface. The adjusted interface looks familiar and comparable to Richard's and Gudrun's Mercedes-Benz and uses a large enough font size making it easily readable for Richard and Gudrun.

On their route to the hotel the intelligent driver profiling system warns Richard about his fatigue and deteriorating awareness before he is aware of it and asks him to take a break and/or to let Gudrun drive the rest of the route. After a small break, Gudrun sits down on the driver's seat, which immediately adjusts to her preferences, and drives them to the hotel. The system is aware of Richard's and Gudrun's departure time and physical conditions, and, consequently, warns Richard without allowing any deterioration of driving performance. To calculate physical conditions, the system may monitor driver characteristics, such as gaze direction, blinking, heart rate, and body posture, and may combine these with general physical conditions, such as age, diseases, and exhaustion. The departure time is known to the profiling system since it might be connected to Richard's and Gudrun's smartphones and might share several information with them, such as schedule, health data, and movement profile. The automatic seat adjustment after Gudrun sits down 
on the driver's seat might function based on a facial recognition system identifying Gudrun and automatically initiating adjustments.

This scenario illustrates the potential of an intelligent driver profiling system for cars. Richard and Gudrun experience a less stressful and less exhausting journey. Thus, they are a lot more motivated to undertake another trip in near future. In conclusion, the intended system may facilitate driving an unfamiliar car enormously and, hereby, smooth the way for MAAS where driving unfamiliar cars will be the rule rather than the exception.

\section{$4 \quad$ Summary and Conclusion}

A large amount of ADAS is already available in current high-end cars and these systems will distribute even further within the next several years [9]. This paper presents a basic concept of an intelligent driver profiling system for cars as an additional assistance system that customises and personalises car features and other ADAS. First, a short introduction to the state of the art of the areas automotive sensors, ADAS, driver behaviour profiling, and driver state monitoring, is given. Their importance and potential application for the intended system is outlined and, in this way, the framework of the profiling system is illustrated. Subsequently, the motivation of the system is pointed out; the move towards MAAS is inevitable and will change the way people use cars. A profiling system assists this shift and increases business as well as customer satisfaction and safety. The main functions of the intelligent driver profiling system are to identify the user, to create a profile based on entered settings and gathered data, and to tailor all adjustable areas of a car based on this profile. The goal of the profiling system is visualized by using a persona and presenting challenges faced in current cars which, however, can be met with an intelligent profiling system.

An intelligent driver profiling system for cars has great potential to benefit customers as well as manufacturers and should therefore be researched further. Identifying adjustable areas in the car, testing adjustments, and evaluating their performance will constitute important parts of further research. After identification of beneficial areas of adjustment, a thorough analysis of automotive sensors must be performed to define personalisable areas and the extent of personalisation in these areas. A compromise between personalisation and customisation has to be elaborated to ensure robustness and proper functioning. Following this, a testing platform will be created to run early stage trials for acceptance, usability and preferences. The findings will be analysed and modelled to generate design guidance material supporting the detailed creation of an intelligent driver profiling system for cars which is based on personalisation and customisation.

\section{References}

1. Green P (2008) Motor vehicle driver interfaces. In: Sears A, Jacko JA (eds) Hum.-Comput. Interact. Handb. Fundam. Evol. Technol. Emerg. Appl., 2nd ed. Lawrence Erlbaum Assoc, New York, pp 701-719 
2. Treat JR, Tumbas NS, McDonald ST, Shinar D, Hume RD, Mayer RE, Stansifer RL, Castellan NJ (1979) Tri-level study of the causes of traffic accidents - final report. 82

3. Riemer K, Totz C (2003) The many faces of personalization. In: Cust. Centric Enterp. Adv. Mass Cust. Pers. Springer, Berlin, Heidelberg, pp 35-50

4. Arora N, Dreze X, Ghose A, et al (2008) Putting one-to-one marketing to work: personalization, customization, and choice. Mark Lett 19:305-321

5. Moniri MM, Feld M, Müller C (2012) Personalized in-vehicle information systems: building an application infrastructure for smart cars in smart spaces. In: Eighth Int. Conf. Intell. Environ. IEEE, pp 379-382

6. Wockatz P, Schartau P (2015) IM travellers needs and UK capability study: supporting the realisation of intelligent mobility in the UK. Transport Systems Catapult, Milton Keynes, UK

7. Shaheen S, Cohen A (2007) Growth in worldwide carsharing: an international comparison. Transp Res Rec J Transp Res Board 1992:81-89

8. Martin E, Shaheen S, Lidicker J (2010) Impact of carsharing on household vehicle holdings: results from North American shared-use vehicle survey. Transp Res Rec J Transp Res Board 2143:150-158

9. Bengler K, Dietmayer K, Färber B, Maurer M, Stiller C, Winner H (2014) Three decades of driver assistance systems: review and future perspectives. IEEE Intell Transp Syst Mag 6:6-22

10. Fagnant DJ, Kockelman KM (2014) The travel and environmental implications of shared autonomous vehicles, using agent-based model scenarios. Transp Res Part C Emerg Technol 40:1-13

11. Fleming WJ (2008) New automotive sensors - a review. IEEE Sens J 8:19001921

12. D'Orazio L, Visintainer F, Darin M (2011) Sensor networks on the car: state of the art and future challenges. In: Des. Autom. Test Eur. Conf. Exhib. DATE. IEEE, pp 1-6

13. Fleming WJ (2001) Overview of automotive sensors. IEEE Sens J 1:296-308

14. Abdelhamid S, Hassanein HS, Takahara G (2014) Vehicle as a Mobile Sensor. Procedia Comput Sci 34:286-295 
15. Piao J, McDonald M (2008) Advanced driver assistance systems from autonomous to cooperative approach. Transp Rev 28:659-684

16. Ziebinski A, Cupek R, Erdogan H, Waechter S (2016) A survey of ADAS technologies for the future perspective of sensor fusion. In: Nguyen NT, Iliadis L, Manolopoulos Y, Trawiński B (eds) Comput. Collect. Intell. Springer International Publishing, Cham, pp 135-146

17. Itoh M, Horikome T, Inagaki T (2013) Effectiveness and driver acceptance of a semi-autonomous forward obstacle collision avoidance system. Appl Ergon 44:756-763

18. Sun B, Akamatsu K, Nagai T (2016) Advanced driver assistance system for vehicle. 18

19. Lorber A (2012) Driver profiling. 16

20. Castignani G, Derrmann T, Frank R, Engel T (2015) Driver behavior profiling using smartphones: a low-cost platform for driver monitoring. IEEE Intell Transp Syst Mag 7:91-102

21. Van Ly M, Martin S, Trivedi MM (2013) Driver classification and driving style recognition using inertial sensors. In: Intell. Veh. Symp. IV 2013 IEEE. IEEE, Australia, pp 1040-1045

22. Carmona J, García F, Martín D, Escalera A, Armingol J (2015) Data fusion for driver behaviour analysis. Sensors 15:25968-25991

23. Meiring G, Myburgh H (2015) A review of intelligent driving style analysis systems and related artificial intelligence algorithms. Sensors 15:30653-30682

24. Joubert JW, de Beer D, de Koker N (2016) Combining accelerometer data and contextual variables to evaluate the risk of driver behaviour. Transp Res Part F Traffic Psychol Behav 41:80-96

25. Jelbert R, Heavyside G (2017) Driver profiling system and method. 29

26. Castignani G, Frank R, Engel $\mathrm{T}$ (2013) Driver behavior profiling using smartphones. In: Proc. 16th Int. IEEE Annu. Conf. Intell. Transp. Syst. ITSC 2013. IEEE, The Hague, The Netherlands, pp 552-557

27. Engelbrecht J, Booysen MJ, van Rooyen G-J, Bruwer FJ (2015) Survey of smartphone-based sensing in vehicles for intelligent transportation system applications. IET Intell Transp Syst 9:924-935 
28. Toledo T, Musicant O, Lotan T (2008) In-vehicle data recorders for monitoring and feedback on drivers' behavior. Transp Res Part C Emerg Technol 16:320331

29. Musicant O, Bar-Gera H, Schechtman E (2010) Electronic records of undesirable driving events. Transp Res Part F Traffic Psychol Behav 13:71-79

30. Boverie S, Giralt A (2008) Driver vigilance diagnostic based on eyelid movement observation. In: Proc. 17th World Congr. Int. Fed. Autom. Control. Seoul, Korea, pp 12831-12836

31. May JF, Baldwin CL (2009) Driver fatigue: the importance of identifying causal factors of fatigue when considering detection and countermeasure technologies. Transp Res Part F Traffic Psychol Behav 12:218-224

32. Rauch N, Kaussner A, Krüger H-P, Boverie S, Flemisch F (2009) The importance of driver state assessment within highly automated vehicles. Proc. 16th ITS World Congr.

33. Friedrichs F, Yang B (2010) Camera-based drowsiness reference for driver state classification under real driving conditions. In: 2010 IEEE Intell. Veh. Symp. San Diego, California, USA, pp 101-106

34. Dong Y, Hu Z, Uchimura K, Murayama N (2011) Driver inattention monitoring system for intelligent vehicles: a review. IEEE Trans Intell Transp Syst 12:596614

35. Horrey WJ, Lesch MF, Dainoff MJ, Robertson MM, Noy YI (2012) On-board safety monitoring systems for driving: review, knowledge gaps, and framework. J Safety Res 43:49-58

36. Gonçalves J, Bengler K (2015) Driver state monitoring systems- transferable knowledge manual driving to HAD. Procedia Manuf 3:3011-3016

37. Ma Z, Mahmoud M, Robinson P, Dias E, Skrypchuk L (2017) Automatic detection of a driver's complex mental states. In: Gervasi O, Murgante B, Misra S, Borruso G, Torre CM, Rocha AMAC, Taniar D, Apduhan BO, Stankova E, Cuzzocrea A (eds) Comput. Sci. Its Appl. - ICCSA 2017. Springer International Publishing, Cham, pp 678-691

38. Maguire M (2001) Methods to support human-centred design. Int J Hum-Comput Stud 55:587-634

39. Langdon P, Thimbleby H (2010) Inclusion and interaction: designing interaction for inclusive populations. Interact Comput 22:439-448 
40. Clarkson PJ, Coleman R (2015) History of inclusive design in the UK. Appl Ergon 46:235-247

41. Walker GH, Stanton NA, Salmon PM (2015) Human factors in automotive engineering and technology. Ashgate, Farnham Surrey, England; Burlington, VT 